THE WORLD BANK ECONOMIC REVIEW, VOL. 12, NO. 2: 271-295

\title{
Regional Integration as Diplomacy
}

\author{
Maurice Schiff and L. Alan Winters
}

Regional integration agreements are examples of second-best policies and have an ambiguous impact on welfare. This article builds a model in which regional integration agreements unambiguously raise welfare by correcting for externalities. It assumes that trade between neighboring countries raises trust between them and reduces the likelihood of conflict. The optimum intervention in that case is a subsidy on imports from the neighbor. The article shows that an equivalent solution is for the neighboring countries to tax imports from the rest of the world - that is, to form a regional integration agreement-together with some domestic taxes.

The article shows that (1) the optimum tariffs on imports from the rest of the world are likely to decline over time; (2) deep integration implies lower optimum external tariffs if it is exogenous; (3) optimum external tariffs are higher before deep integration and lower thereafter if deep integration is endogenous; and (4) enlargement of bloc size (in terms of symmetric countries) has an ambiguous impact on external tariffs but raises welfare, and some form of domino effect exists.

Il n'y aura de paix en Europe si les Etats se reconstituent sur une base de souveraineté nationale avec ce que cela entraine de politique de prestige et de protection économique ... la constitution de vastes armées sera à nouveau nécessaire ... L'Europe se recréera une fois de plus dans la crainte . . à moins que les Etats d'Europe ne se forment en une Fédération ou une "entité européenne" qui en fasse une unité économique commune. ${ }^{1}$

As has long been known, regional integration agreements (RIAs) are examples of second-best policies, and their impact on economic welfare is ambiguous. Despite an enormous theoretical, empirical, and historical descriptive literature, no consensus on the desirability of RIAs has emerged.

1. "There will be no peace in Europe if the States reconstitute themselves on a basis of national sovereignty with its policies of prestige and economic protection.... The constitution of large armies will again be necessary . . . Europe will once again be recreated in fear . . unless the States of Europe join in a Federation or a 'European entity' that results in a common economic unit." Jean Monnet, 5 August 1943, as quoted in Rieben, Monnet, and Chevallaz (1971) and translated by the authors. The idea that commercial ties will reduce the risk of European wars dates back at least to the 1795 publication of Kant's Perpetual Peace (Kant 1992).

Maurice Schiff and L. Alan Winters are with the Development Economics Research Group at the World Bank. The authors would like to thank the referees and participants in seminars at the World Bank and in the 1997 meetings of the American Economic Association for useful comments. This article was produced as part of the World Bank Development Economics Research Group's research program on regionalism and development.

O 1998 The International Bank for Reconstruction and Development / THE WORLD BANK 
One of the few unambiguous static results that has emerged is that, in the case of homogeneous products, an RIA between small countries whose terms of trade are given exogenously will result in a welfare loss for the RIA as a whole as long as its members continue to trade with the rest of the world after forming the RIA (Bhagwati and Panagariya 1996 and Schiff 1997). Even this result need not hold in the presence of smuggling (Schiff 1997).

Given the ambiguity of the static welfare impact of RIAs and their generally small estimated size, many commentators have appealed to dynamic effectssuch as those on foreign direct investment, economies of scale, and convergenceto justify them. Whether these dynamic effects actually take place as a result of RIAs, however, has not been demonstrated conclusively either analytically or empirically (see, for example, Vamvakidis, this issue). And even if they do occur, they need not result in welfare gains. For instance, increased foreign direct investment may result in immiserization if it leads to the expansion of protected sectors. Related arguments have been made that regional trading arrangements might enhance developing countries' efforts to industrialize (see Puga and Venables 1997 and this issue for the first formalization of this idea).

However, RIAs generate unambiguous welfare gains even in terms of static welfare theory when they correct externalities. For instance, it is frequently claimed that a developing country in the process of reforming its trade and other policies can benefit from an RIA with a large, developed country or region (such as the United States or European Union) because the RIA binds the country's reforms in an international treaty, weakens the groups that stand to lose from and oppose the reforms, and raises the reforms' credibility. If the beneficial reformsupport effects outweigh the traditional deadweight loss effects, an RIA may increase economic welfare. (See Fernández's article in this issue for an insightful discussion of these arguments.)

Another kind of externality arises when an RIA improves security for its member countries. There are basically three types of situations in which RIAs may generate such positive externalities. First, there may be domestic security threats such as civil disruption or civil war. For instance, the Egyptian government has been concerned with the spread of fundamentalism, and the governments of Morocco and Tunisia have been concerned that fundamentalism in neighboring Algeria, with the associated risk of civil strife, may be contagious. These issues, which have also been of concern to the European Union, have provided one of the motivations for agreements between these Mediterranean countries and the European Union.

Second, countries may respond to security threats from third countries by forming a regional arrangement. For instance, the Southern African Development Coordination Conference, which eventually developed trading arrangements under the Southern African Development Community, was formed to provide a united front against the Republic of South Africa. ${ }^{2}$ The Gulf Coopera-

2. See Table A-1 in Schiff and Winters' introduction to the symposium (this issue) for a list of regional trade agreements and their member countries. 
tion Council was created partially in response to the potential threat of regional powers such as Iran and Iraq. And Central and Eastern European countries have applied for membership in the European Union partly as protection against the perceived threat from Russia.

Third, security threats may move neighboring countries to form RIAs. For example, the European Coal and Steel Community (ECSC in 1951) and the European Economic Community (in 1957) were created to reduce the threat of war in Europe (see the quote of Jean Monnet at the start of this article), the Association of South East Asian Nations (ASEAN) was created to reduce tensions between Indonesia and Malaysia, and Mercosur (a regional trade agreement among Argentina, Brazil, Paraguay, and Uruguay) was created to reduce tensions between Argentina and Brazil (see Bastian 1996). Page (1996) suggests that this motivation also prompted the formation of the Asia-Pacific Economic Cooperation Process and the Central American Common Market, which include potential political/military opponents.

Despite the frequency with which such motivation is claimed for RIAs, not only by politicians but by academic commentators as well (see, for example, Swann 1992), it has, to our knowledge, never been subjected to formal analysis and still less to empirical test. Our purpose is to start this process by analyzing a formal model of an RIA motivated by (intermember) security concerns and by deriving predictions about observable phenomena that could, in principle, be tested. Four major predictions are derived in this article. Assuming that trade can help to reduce frictions among hostile neighboring countries, we show that

- An RIA is an optimum (first-best) arrangement in traditional, static welfare terms

- The optimum external tariffs fall over time

- The optimum external tariffs fall following deep integration (defined as integration measures that go beyond trade policy, including harmonization and mutual recognition of standards, investment codes, and other measures that increase market contestability and lower the cost of trade)

- Enlargement raises member countries' welfare, and optimum external tariffs are likely to rise.

Our purpose is not to advance the argument that trade is a route to rapprochement between antagonistic states, but rather to take this argument at face value and explore whether an RIA can generate welfare gains under these conditions and to predict how such an RIA would evolve. First, we demonstrate that such welfare-enhancing RIAs exist. Second, we generate predictions about the development of regional integration. Finally, we identify theoretical predictions about observable phenomena that might allow investigators to test whether particular RIAs were motivated by a concern for security. For example, the fact that during its 40-year history the European Union has regularly reduced its tariffs on nonmembers is consistent with our predictions. Because other explanations exist, this obviously cannot prove our hypothesis, but it 
lends credence to the conclusion that intermember security was a factor behind European integration.

Identifying the motivation for an RIA does not alter its economic and political effects but does allow a more rational discussion of policy options. Many policies that are economically costly are justified on political or security grounds. If our test suggests that, in fact, behavior is not consistent with security concerns, it would be more difficult to dismiss economic considerations. See Winters (1989, 1991) for a similar approach to agricultural trade policies.

We view this article as only a first step toward formalizing the link between intermember security and regional integration. We wish to show that formalization can generate hypotheses that can be tested empirically. We use the simplest framework that incorporates the links cited by advocates and explore their implications.

Section I explores the argument that integration fosters security, and this is translated into a formal model in section II. (The model provided in this article abstracts from defense as an alternative means of providing security. This issue is on our research agenda, as is discussed in section VIII.) The solution is provided in section III (under symmetry and under asymmetry). The relationship between both autonomous and endogenous deep integration and optimum external trade policy is examined in section IV. Dynamic aspects are examined in section V. Bloc enlargement and domino effects are examined in section VI. Section VII concludes, and section VIII discusses possible extensions. Finally, technical derivations are included in appendixes $\mathrm{A}, \mathrm{B}$, and $\mathrm{C}$.

\section{Trade AND Security}

The notion that trade is a civilizing influence is an old one (see Hirschman 1982). The notion that international trade can diffuse tension and bring nations together is also venerable. The nineteenth-century British politician Richard Cobden persistently advocated that Great Britain should trade freely with its neighbors as a means of convincing them of the advantages of free trade and also as a means of locking them more fully into the community of nations. In the twentieth century, Cordell Hull, U.S. secretary of state (1933-44) and an architect of the postwar international trading order, advocated this view throughout his public life. His autobiography contains homely stories of trade reconciling warring neighbors along with discussions of international strategy (Hull 1948). ${ }^{3}$ However, both Cobden and Hull were strongly committed to nondiscrimination. Thus, although the Cobden-Chevalier Treaty of 1860 between France and Great Britain was bilateral, Cobden's conception was multilateral, and the treaty

3. For a contrary position, see Keynes, who stated that "I sympathize . . . with those who would minimize rather than those who would maximize economic entanglement between nations. Ideas, knowledge, art, hospitality, travel一these are the things which should of their nature be international" (see Skidelsky 1992: 476-80). 
itself contained an unconditional most-favored-nation clause. Hull was explicit that trade discrimination bred rather than diffused tension (Hull 1948). ${ }^{4}$

For advocacy of regionalism on security grounds, we turn to continental Europe. Wilfredo Pareto argued in 1889 that "Customs unions . . . [were] . . . a means to better political relations and eventual pacification" (Machlup 1977: 41), and Robert Schuman and Jean Monnet, the founding fathers of the European Economic Community, were explicit that the ECSC was to make FrancoGerman war not only "unthinkable, but materially impossible" (see Swann 1992: 6). Monnet also argued that while Great Britain, the United States, and the Soviet Union could withdraw into their own spheres, France and Germany were inextricably linked and had no alternative than to solve the "European problem."

Later echoes of Monnet's views are common. For example, Dr. Walter Hallstein, a former president of the European Community Commission, has put it clearly: "We are not in business at all; we are in politics" (see Swann 1992: ix). And Jones (1993: 83), referring to France and Germany, states that "Some trading blocs may be advocated primarily to avoid military conflicts." Hirschman (1981: chap. 12) makes a similar point, although he argues that the European Community may have arrived a bit late.

Jones (1993) also argues that, because open markets imply a loss of national control over the economy, countries may prefer to form RIAs with like-minded neighbors. In other words, the issue of cultural externalities (where people benefit from interacting with a larger number of similar people) may influence the choice of partner as well as the decision to form an RIA. For instance, one suggestion for why a number of North African countries have chosen to form RLAs with the European Union rather than liberalize unilaterally is that unilateral liberalization would subject them to open competition with Asia and possibly threaten their lifestyle. The analysis provided in this article applies to cultural externalities as well. Switzerland, by contrast, found an alternative way to generate security through neutrality and has so far been reluctant to join the European Union.

Security and other noneconomic aspects of RIAs also seem to have played a role in the Southern Cone. Argentina and Brazil signed nuclear cooperation and economic agreements in the area of capital goods and automobiles in the mid1980 s, with each quite possibly hoping that reducing external tensions would allow it to reduce the power of its military and strengthen its fragile democracy. The creation of Mercosur in 1991 continued this process and drew smaller neighboring countries into it. Recent rumors that a possible coup in Paraguay was laid to rest following reaffirmation by the presidents of the four member countries that democracy was a necessary condition for membership in the bloc, based on a clause in the Treaty of Asunción establishing Mercosur, has been cited as evidence of the political effectiveness of Mercosur ("Survey on Mercosur," The Economist, October 12, 1996).

4. He advocated the principle of unconditional most-favored-nation status, which in U.S. usage implies offering most-favored-nation tariffs to any country offering most-favored-nation status to the United States. That is, it continues to permit discrimination against those outside the system. 
Srinivasan (1994: 7) argues that integration might help to reduce tensions in South Asia: "It is conceivable that promoting freer movement of goods, services, people, and capital in the region might also facilitate the resolution of political and territorial disputes." We focus on the movements of goods and services.

A direct link between regionalism and security arises if a regional agreement makes access to the partners' supplies more secure by reducing the threat of a trade embargo. Arad and Hillman (1979) show how fear of being cut off from foreign sources of defense equipment can cause countries to overinvest (relative to comparative advantage) in their own defense industries. Similarly, Hillman and van Long (1983) consider the optimal exploitation of a mineral resource if the alternative foreign supply is uncertain. In both these cases, an RIA that assures partners' supplies would be advantageous through its effect on members' allocation of resources, which is a different effect from our pacification hypothesis. But although these authors do not consider this explicitly, an RIA that makes access to partners' supplies more secure could reduce the likelihood of a country using conquest to ensure access. As stated by Keynes (1919: 99), "In a regime of free trade and free economic intercourse, it would be of little consequence that iron lay on one side of a political frontier and labor, coal, and blast furnaces on the other."

Political scientists have also discussed the use of trade diplomacy within a regional context, including whether and what type of RIAs might raise welfare of the member countries through intramural conflict avoidance and management. Bastian (1996) argues that trade negotiations between leaders of neighboring countries are likely to result in a higher degree of trust between them. He mentions that RIAs may enable "political and/or economic elites to form coalitions for subsequent collaboration and consensual action" and that they may "carry their own language and discourse, thus being able to socialize the participants, e.g., when talking about a 'region.' " Mansfield (1993) also recognizes the importance of security externalities in trade relations. However, he argues that countries will lower barriers with other countries that belong to the same alliance (for example, the North Atlantic Treaty Organization) because the increased trade will raise incomes, which can then be used to pay for defense expenditures. Contrary to Mansfield, we assume that the very action of trading generates security benefits between adversaries or friends and note that Mansfield's analysis is weakened by the fact that trade preferences have an ambiguous impact on income. On this issue, see also Mansfield and Bronson (1997).

Evidence is limited of the impact of trade on the likelihood of conflict between countries. Numerous studies in the political science literature have confirmed the results of Chan (1984) that conflict is less prevalent between two countries if both are democratic. Polachek $(1992,1996)$ explains this finding through the effect of democracy on trade. He finds that democracies trade more with each other than with other countries and, using data from the Conflict and Peace Data Bank, finds a significant and negative relationship between trade and conflict. He obtains an elasticity of his measure of conflict with respect to 
trade of -0.15 to -0.19 . Polachek tests the direction of causality by means of three-stage least squares and finds that the trade variable remains statistically significant and becomes more important (elasticity of -0.30 ) in the conflict equation, while the conflict variable is not significant in the trade equation. These causality results are confirmed by Granger causality tests (Gasiorowski and Polachek 1982).

In this article, we refer to RIAs in a geographic sense or to what Ethier (1996) has called "regional regionalism." This definition would seem to cover most RIAs because they are generally formed among neighboring countries. Examples include the European Union, Mercosur, the Andean Pact, the Central American Common Market, the North American Free Trade Agreement (NAFTA), ASEAN's Asian Free Trade Agreement, the South Asian Free Trade Agreement, the Gulf Cooperation Council, the Economic Community of West African States, and the Southern African Development Community. Our analysis is thus of potential relevance for the majority of RIAs.

Although the rest of this article formalizes the role of trade in rapprochement, a similar role can be claimed for other forms of economic relations. For example, mutual investment or migration flows can stimulate trust, as can the meetings between national civil servants that are necessary for policy cooperation (see Winters 1997). RIAs frequently promote these forms of contact either directly or indirectly, and their analysis would be very similar to that which follows, that is, the acceptance of economic costs-investment from partners rather than from the rest of the world or constraints on policy discretion-in return for security benefits. Most of the literature and political discourse focuses on trade, however, perhaps because capital mobility was not a strong feature of the 1940s or 1950s when the Europeans were formulating these ideas and perhaps also because resource ownership, migration, and the intermixing of political elites are more intrusive and harder to sell politically than trade.

\section{A Trade Model with Security Benefits}

The idea of the model is very straightforward: international trade with a potentially hostile partner generates a positive externality-security-that individual traders cannot appropriate. As a result, private decisions generate suboptimal levels of trade with such partners, calling for a subsidy on trade with partners. Taxing domestic commerce and trade with countries other than the partner can be equivalent to this subsidy, and so an RIA is born. We formalize this idea in this and the next section. Subsequent sections extend the idea to treat issues of deep integration, dynamics, and enlargement.

Assume three countries $(1,2$, and the rest of the world, ROW) and three normal goods (A, B, and R). Country 1 produces good A, country 2 produces good B, and ROW produces goods A, B, and R. We abstract from optimal taxation issues related to economic power on the world market in order to focus 
exclusively on matters of security and trade diplomacy. ${ }^{5}$ Hence, we assume that countries 1 and 2 are small and that the world prices, $P_{A}^{*}, P_{A}^{*}$, and $P_{R}^{*}$, they face are determined in ROW. Without loss of generality, units of $A, B$, and $R$ are selected such that $P_{A}^{*}=P_{B}^{*}=P_{R}^{*}=1$. Output in country $1(2)$ is given exogenously and equals national income $Y_{1}\left(Y_{2}\right)$ measured at world prices.

Denote consumer prices of goods A, B, and R in country $i(i=1,2)$ by $P_{A}^{i}, P_{B}^{i}$, and $P_{R}^{i}$, respectively. Assume a representative consumer in country $i$, whose consumption of goods $\mathrm{A}, \mathrm{B}$, and $\mathrm{R}$ is denoted by $A_{i}, B_{i}$, and $R_{i}$ and who derives utility from the consumption of goods and from social capital in the form of (collective) security. Thus:

$$
\begin{aligned}
U_{i}=V\left(A_{i}, B_{i}, R_{i}\right)+Z_{i}\left(S K_{t}\right) ; i=1,2, \\
V_{i}, Z_{i}^{\prime}>0, V_{i j}, Z_{i}^{\prime \prime}<0, V_{i}(j=0)=\infty, V_{j} \equiv \partial V / \partial j\left(j=A_{i}, B_{i}, R_{i}\right), \text { and } \\
Z_{i}^{\prime} \equiv \partial Z_{i} / \partial S K_{t}
\end{aligned}
$$

with $U_{i}$ twice continuously differentiable. The assumption that $V_{1}(0)=\infty\left(j=A_{i}\right.$, $B_{i}, R_{i}$ ) ensures internal equilibrium in the sense that countries 1 and 2 trade both with each other and with ROW no matter what taxes or subsidies are applied.

$S K_{i}$ denotes the level of security in country $i$ that is associated with trust in the neighboring country or the level of security capital in country $i$. We assume that utility increases at a decreasing rate as the level of security increases $\left(Z_{i}^{\prime \prime}<0\right)$. Security $S K_{l}$ is a public good that our representative consumer takes as given when maximizing $U_{i}$.

The welfare impact of incorporating a public good $S K_{i}$ (social capital) in the utility function is examined in the case of labor mobility in Schiff (1992) and in the case of international migration in Schiff (1996). Becker (1996) and Bliss (1994) also assume that social capital enters the utility function. It could equally well have been incorporated into the production functions for goods $A$ and $B$ rather than in the utility function, with a lower degree of security implying that more resources must be devoted to security matters and fewer are available for the production of goods A and B. This approach is taken in Schiff $(1995,1998)$, which examine the impact of policy reform under ethnic diversity.

We refer below to countries 1 and 2 as partners whether or not they are members of an RIA. We assume that an increase in home-country imports from the partner reduces the level of insecurity in the home country. In other words, importing from the partner country increases interaction with individuals in the partner country, raises the level of information about them, and increases the level of trust and security in the home country. ${ }^{6}$ Alternatively, one might postu-

5. See Krugman (1991) for an analysis of customs unions' optimal common external tariffs associated with market power.

6. The level of home-country imports of the partner's good equals the level of home-country consumption of that good, which is not produced there. In fact, $S K$ depends on total rather than per capita imports from the partner, so the term $L_{i}$ should be included in the equation. Expressing $S K$ as a function of per capita imports does not affect the model's solution (although it matters in the case of population changes) and is done for notational simplicity. 
late that larger home-country imports from the partner raise the importance of the home country as a market for the partner's exports and lowers the likelihood of a security threat by the partner country. Thus,

$$
S K_{1}=S K\left(B_{1}\right) ; S K_{2}=S K\left(A_{2}\right)
$$

with $S K$, twice continuously differentiable and $S K_{1}\left(S K_{2}\right)$ increasing in $B_{1}\left(A_{2}\right)$ and strictly concave.

Keynes (1919: 30-32) describes how France continued to see Germany as a threat in 1919 -even though Germany lost the war-because Germany's wealth and population had grown much faster than France's between 1870 and 1914. Thus a neighbor's relative power (such as wealth and population) also affects security. Such a term could easily be added in equation 2 . It is not done for simplicity, although implications are discussed in section III.

The discussion so far has been about the security benefits of trade with a neighboring country, while equation 2 expresses security as a function of imports rather than trade. Assuming that security is a function of imports rather than trade simplifies the analysis but has no effect on the main findings. This issue is discussed further at the end of section III and in section VIII.

\section{Equilibrium and Optimal Trade Solutions}

Our representative consumer maximizes utility $U_{i}$ with respect to $A_{i}, B_{i}$, and $R_{i}$, subject to the budget constraint $Y_{i}=P_{A}^{i} A_{i}+P_{B}^{i} B_{i}+P_{k} R_{i}$, taking $S K_{i}$ as given exogenously $(i=1,2)$. As usual, the individual's first-order conditions are

$$
V_{A}^{i} / V_{R}^{i}=P_{A}^{i} / P_{R}^{i} ; V_{B}^{i} / V_{R}^{i}=P_{B}^{i} / P_{R}^{i} ; i=1,2
$$

Given our choice of units, in the absence of domestic or trade taxes in countries 1 and $2, P_{i}^{i}=P_{i}^{*}=1\left(i=1,2 ; j=A_{i}, B_{i}, R_{l}\right)$, so that utility maximization implies

$$
V_{A}^{i} / V_{R}^{i}=V_{B}^{i} / V_{R}^{i}=1 \text {. }
$$

This maximizes national income $L_{i} V_{i}$, that is, the part of welfare $W=L_{i} U_{i}$, that depends directly on the consumption of goods and services (where $L_{i}$ is the population of country $i$ ). However, welfare also depends on benefits from security, $L_{i} Z_{i}$, which is not a choice variable for the representative consumer. Thus while individual utility maximization requires that $\partial V / \partial j=\partial U / \partial j$ for $\forall j$, social welfare maximization requires that $\partial V / \partial j<\partial U / \partial j$ for $j=B_{1}, A_{2}$, because the home country's social gain from imports from the partner exceeds the private gain by the positive security externality.

It is well known that welfare maximization requires distortions to be attacked at the source (Bhagwati 1987) and that policy should internalize the externalities. In this case, because $S K$ is a function of imports, welfare $W_{i}=L_{i} U_{i}$ in the home country is maximized with a subsidy $S_{i}$ on partner-country imports (assumed to be financed through lump-sum taxation) equal to the externality gen- 
erated by these imports. By standard manipulations, the optimal subsidy is equal to

$$
S_{i}=L_{i}\left(\partial Z_{i} / \partial M_{i}\right) / \lambda_{i}=L_{i}\left(Z_{1}^{\prime} S K_{i}^{\prime}\right) / \lambda_{1}=L_{i}\left(Z_{i}^{\prime} S K_{i}^{\prime}\right) / V_{R}^{i} ; i=1,2
$$

where the numerator equals the externality from an additional unit of imports in country $i, L_{i}\left(\partial Z_{i} / \partial M_{i}\right)(M=$ imports from the partner $)$, and $\lambda_{i}$ is the marginal utility of income that equals $V_{R}^{i} / P_{R}^{*}$ or $V_{R}^{i}$ (because $P_{R}^{*}=1$ ), where $V_{R}^{i}$ is the marginal utility of $R$. Because $P_{A}^{*}=P_{B}^{*}=1$, equation 5 also defines the optimum subsidy rate defined as a share of the world price.

Because countries 1 and 2 continue to trade with ROW following the import subsidy $S_{i}$ (see equation 1 ), the import subsidy does not affect producer prices in countries 1 and 2 . The only effect is to lower the consumer price of imports from the partner.

This is shown for country 1 in figure 1 where all quantities are in per capita terms. $D_{B}^{P}\left(D_{\mathrm{B}}^{S}\right)$ measures the private (social) value of good B for country 1 . The demand price on the social demand curve $D_{B}^{S}$ (that is, the social value) is the sum of the private value and the value of the externality. Following the strict concavity assumptions made in equations 1 and 3 , the vertical distance between the two demand curves falls with $B_{1}$. Private equilibrium in the absence of intervention is at point $\mathrm{E}$, with imports equal to $B_{1}^{P}$, whereas the social optimum is at point $\mathrm{F}$, with imports equal to $B_{1}^{S}$. The latter is obtained with a subsidy on imports of good B from country 2, which lowers the consumer price by the amount of the externality. This is shown in figure 1 by the line $P_{B}^{1}$, which is the world price, $P_{B}^{*}$, minus the import subsidy $\left(P_{B}^{*}-S_{1}=1-S_{1}\right)$, which intersects the private demand curve $D_{B}^{P}$ at point $G$, with subsidy $S_{1}=F G$ and imports, $B_{1}^{S}$.

The relative consumer prices following imposition of the optimal subsidy rate, $S_{i}$, are:

$$
P_{A}^{1} / P_{R}^{1}=1, P_{B}^{1} / P_{R}^{1}=1-S_{1}, P_{A}^{2} / P_{R}^{2}=1-S_{2}, P_{B}^{2} / P_{R}^{2}=1 .
$$

As can easily be verified, the same relative prices can be obtained by trading $B$ freely and imposing instead a tax rate $T_{i}=S_{i} /\left(1-S_{i}\right)$ on imports from ROW and on consumption of the home good (with the tax returned in lump-sum fashion). Thus welfare of country $i(i=1,2)$ is maximized either by imposing a subsidy rate $S_{i}$ on imports from the partner or, alternatively, by countries 1 and 2 forming an RIA with a tariff on imports from ROW of $T_{i}=S_{i} /\left(1-S_{i}\right)$ and an equal tax rate on consumption of the home good.

Even if the tax is imposed exclusively on imports from ROW and not on consumption of the home good, there is a positive tax smaller than $T$, at which welfare is higher than in the absence of interventions, although welfare is lower than with the optimum subsidy $S_{i}$ or with the optimum $\operatorname{tax} T_{i}$ applied to both imports from ROW and to consumption of home goods.

The impact of the optimum intervention on per capita income and welfare can be seen in figure 1 (measured in currency units). Benefits from security $Z_{1}$ 
Figure 1. Equilibrium and Optimal Import Outcomes

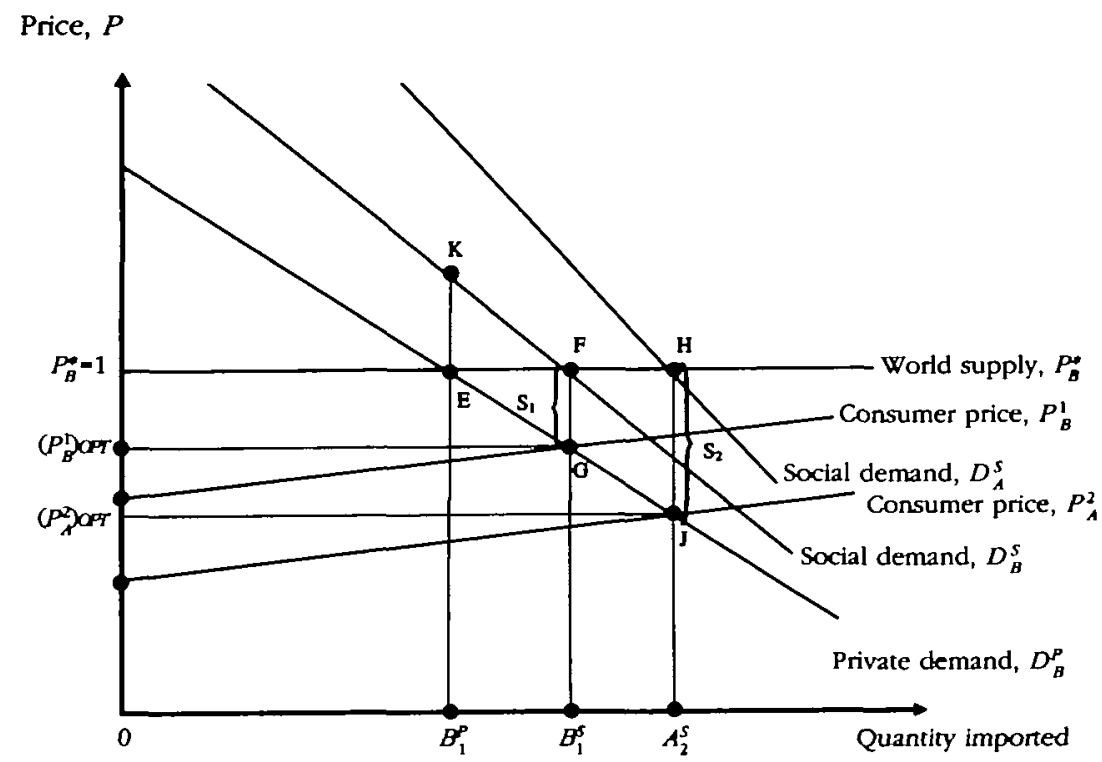

Note: Subscripts $A, B$, and $O P T$ denote good A, good B, and the optimal value, respectively. Superscripts $\bullet, 1,2, S$, and $P$ denote world values, country 1 , country 2 , social values, and private values, respectively.

increase by area $E G F K$, income $V_{1}$ falls by area $E F G$, and welfare $U_{1}$ rises by area $E F K$. Because the security externality is assumed to fall as imports increase, area $E F K$ is larger than area $E F G$. The income loss for country 1 from the RIA can be approximated by $S_{1}^{2} B_{1} \varepsilon_{B} / 2 P 1$, where $\varepsilon_{B}$ is the elasticity of demand for good $B$ in country 1 . Thus, $S_{1}^{2} B_{1} \varepsilon_{B} / 2 P$, the income loss measured as the loss from the RIA relative to a free trade situation, provides a lower bound of the welfare gain $E F K$ that is generated by the optimum intervention.

\section{Symmetry}

If countries 1 and 2 are symmetric, and if the welfare function in goods, $V$, is symmetric in $A$ and $B$, then $B_{1}=A_{2} \equiv M, S K_{A}=S K_{B} \equiv S K$, and $U_{A}=U_{B}=V(M, M$, $R)+Z[S K(M)]$. Then the optimum subsidy rate on partner imports $(S)$ is the same for each country, and optimality can also be achieved through the formation of a customs union between countries 1 and 2 with a common external tariff rate CET $=S /(1-S)$ and with a tax rate $T=$ CET on consumption of the home good. In the symmetric case, trade between the partners is balanced and so is their trade with ROW. This is not the case under asymmetry.

\section{Asymmetry}

Now assume symmetry between countries 1 and 2, with the exception being that increasing security is more important to country 2 than to country 1 . That 
is, for any $S K_{1}=S K_{2}, Z_{2}^{\prime}>Z_{1}^{\prime}$. This may be due to the fact that country 1 has a stronger tendency to resort to aggression to resolve disagreements or that country 2 suffered more in previous wars than country 1 . For instance, France may have been more concerned with security than Germany in the first half of the twentieth century, while the opposite may have been true in Napoleonic times. The equilibrium in the previous subsection is no longer sustainable because country 2 now desires a larger subsidy: that is, $S_{2}>S_{1}$ (see equation 5).

Alternatively, countries 1 and 2 can maximize welfare by forming a free trade agreement with a tax rate $T_{i}=S_{i} /\left(1-S_{i}\right)$ on imports from ROW and on consumption of the home good and with $T_{2}>T_{1}$ (and rules of origin to prevent deflection of $R$ from country 1 to country 2). Optimum tariffs on imports from ROW are higher for the country with the stronger security concerns. With $S_{2}>S_{1}, B_{1}<A_{2}$. Thus, at the social optimum, country 1 runs a trade surplus with country 2 and a deficit with ROW (and vice versa for country 2 ). In other words, at the social optimum, the country with stronger security concerns imports more from its partner.

This is shown in figure 1. Country 2's private demand curve, $D_{A}^{p}$, is identical to $D_{B}^{P}$. However, because security externalities are higher, the social demand curve for country 2 is $D_{A}^{S}>D_{B}^{S}$, and the price function $P_{A}^{2}$ (equal to the world price minus the optimum subsidy function $S_{2}$ ) intersects the demand curve at point $J$. The subsidy $S_{2}=H J>S_{1}=F G$, and $B_{1}<A_{2}$.

In both the symmetric and asymmetric cases, the welfare of both countries 1 and 2 would also be maximized if one of them applied the optimum subsidy on imports from the partner while the other applied the optimum tax on imports from ROW and on consumption of the home good. The formation of an RIA (customs union or free trade agreement) would require coordination to ensure that both countries 1 and 2 applied the tax. If we add to the model the assumption that policy coordination provides additional security benefits by improving trust and understanding among the leaders (and negotiators) of both countries (see the quote from Bastian 1996 in section I), then an RIA (accompanied by appropriate domestic taxes) would be superior to subsidies on imports from the partner, and welfare-maximizing governments in countries 1 and 2 would coordinate their policies.

There are two additional reasons why coordinated formation of an RIA is likely to be superior. First, security may depend not only on the level of imports but also on the degree of certainty of access. The formation of an RIA requires policy coordination, including signing of an international treaty, and should therefore provide more security of access to the neighbor's goods and services than a situation in which each country determines policy entirely independently.

Second, the model assumes that imports from-rather than trade with-the partner country generates security benefits in the home country. If one assumes that total trade (imports plus exports) with the partner generates security benefits, then-due to game-theoretic considerations- RIAs are likely to be superior 
to intrabloc trade subsidies. Individual decisions in the home country generate externalities not only for other individuals of the home country but also for those of the partner country because the home country's imports are the partner's exports and vice versa. Thus intrabloc trade subsidies that maximize national welfare generate a Nash equilibrium, with welfare lower than in a cooperative equilibrium that could be obtained by forming an RIA.

This section has shown that, in the presence of security externalities, the formation of an RIA is an optimal policy. We now examine the implications of the formation of such an optimum RIA for the evolution of external tariffs over time and the effects of deep integration and enlargement. The issue of whether countries 1 and 2 are symmetric or asymmetric has no significant impact on results in the remainder of the article, so unless otherwise noted, symmetry is assumed.

\section{Trade Preferences and DeEp Integration}

It is often argued that the focus on border measures in regional integration may be misplaced if gains from deep integration, such as harmonization of technical standards, investment codes, and legal principles and general facilitation of the movement of goods and factors, are substantial. Deep integration is expected to lower trading costs and break down market segmentation between member countries. The most prominent recent example of deep integration is the European Community's single market program, which was predicted to have much larger economic effects than the mere removal of border policies-see, for example, Smith and Venables (1988), Gasoriek, Smith, and Venables (1992), and Harrison, Rutherford, and Tarr (1996). An unresolved question in the literature is whether regional trade preferences are necessary for or supportive of deep integration on a regional basis. This section examines the relationship between deep integration and trade preferences in the case of autonomous deep integration and in the case of endogenous deep integration.

\section{Autonomous Deep Integration}

Assume that trade is costly and that deep integration occurs autonomously and costlessly and is not related to present or past trade flows or policies. Initially trade with ROW involves the same trading costs, $C$, as intrabloc trade, but following deep integration, intrabloc costs fall to $C_{0}<C$, while those with ROW remain unchanged at $C$. Because (by assumption, see equation 1) trade with ROW continues following deep integration, producer prices in countries 1 and 2 are not affected by deep integration, but consumer prices in the home country for goods imported from the partner ( $B_{1}$ in country 1 and $A_{2}$ in country 2 ) fall by an amount $C-C_{0}$. Consequently, consumption (imports) of $B_{1}$ and $A_{2}$ rises. Given that the marginal security value of imports falls as imports rise (equations 1 and 3), the optimum subsidy $S_{i}$ falls. Graphically, a reduction in trading costs shifts the $P_{B}^{*}$ line in figure 1 downward and thus moves both the intersection points $E$ (of the $P_{B}^{*}$ line and the private demand curve, $D_{B}^{S}$ ) and $F$ (of the $P_{B}^{*}$ line 
and the social demand curve, $D_{B}^{S}$ ) to the right. Because the distance $F G=S_{1}$ falls as $B_{1}$ rises, the optimum subsidy falls.

Equivalently, lower trading costs on intrabloc trade imply lower optimum taxes on trade with ROW and on consumption of home goods. Thus, in the case of exogenous deep integration within the region, trade preferences and deep integration are substitutes: lower intrabloc trading costs imply lower optimum trade preferences.

\section{Endogenous Deep Integration}

Alternatively, assume that lowering trade frictions on intrabloc trade is costly and requires a conscious policy decision. Assume also that the cost is negatively related to the level of trust or security capital $S K$. Because trust is positively related to imports from the partner, a larger volume of such imports reduces the cost of deep integration and thus is likely to result in more deep integration and in lower unit trading costs on trade with the partner. Haas (1958: 311) saw increased trade among members of the EC-6 (Belgium, France, Germany, Italy, Luxembourg, and Netherlands) positively affecting both international politics and deep integration: "It is inconceivable that the liberalization not only of trade but of the conditions governing trade can go on for long without 'harmonization of general economic policies' spilling over into the fields of currency and credit ... The spillover may make a political community of Europe."

We examine two alternative scenarios. In the first, deep integration takes place every period. In the second, deep integration takes place once. Assume first that unit trading costs on imports from the partner are related to the current level of imports. In this case, two sources of positive externalities-rather than one-are associated with imports from the partner. Consumers who import from the partner generate both a security externality by raising utility directly (equation 1 ) and an indirect cost externality by lowering the unit cost of intrabloc trade. With a greater overall positive externality than in the previous cases without deep integration, the optimal subsidy or external tariff is higher. (See appendix A for a formal derivation of this result.)

Alternatively, assume that deep integration takes place at a given point in time (for example, in 1992 for the EC-92) and is permanent. For instance, assume that trust and security, $S K_{i}$, depend not only on the flow of current intrabloc trade but also on past flows (see section $V$ ) and that deep integration will take place when $S K$, is sufficiently large and therefore the cost of deep integration is sufficiently low. The optimum subsidy now changes through time. Because increased intrabloc trade initially generates externalities by lowering the cost of future deep integration, the optimum subsidy on intrabloc trade (or optimum CET) is higher before deep integration than it would be in its absence. However, once deep integration has taken place and intrabloc trading costs have fallen, imports are naturally higher, and the optimum subsidy (or optimum CET) is lower than in the absence of deep integration. (The results can be derived formally in a dynamic optimal-control-type framework such as in appendix B.) 
To summarize, if the cost of deep integration is not related to the degree of trust between countries 1 and 2 (our autonomous case), not only are trade preferences not required in order to implement deep integration measures, but deep integration implies a reduction in optimum trade preferences. However, if deep integration needs to be replenished every period and its cost declines with the degree of security and trust, optimum trade preferences are larger. Finally, if deep integration takes place once and for all and is permanent, optimum trade preferences are higher before deep integration takes place and lower thereafter.

\section{Dynamic Adjustments to a Steady State}

The European Community has reduced its external trade barriers on manufacturing products with respect to ROW over time. The European Community's external trade barriers have fallen over time even as the number of member countries has grown from 6 to 15, that is, despite the increase in the optimum CET level based on market power considerations. Average tariffs on manufacturing products have fallen from about 13 percent in 1958 to about 3 percent after the Uruguay Round. Similarly, developing countries forming RIAs in the 1960s imposed high external trade barriers while recent RIAs and new incarnations of old RIAs have tended to impose lower external trade barriers. Is this gradual reduction of external trade barriers over time predicted by our model of regional integration?

In our main model, security capital $(S K)$ is assumed to depend on the current flow of imports from the partner and to depreciate fully at the end of each period. However, security could depend on past behavior as well, that is, it would not depreciate entirely at the end of every period. We can think of this as the level of $S K_{t}$ at time $t$ depending positively on both the current flow of imports from the partner and on $S K_{t-1}$ at $t-1$, with a rate of depreciation of $S K$ equal to $\delta<1$ per period. We provide here an intuitive solution to this problem; appendix $B$ provides a formal derivation.

This case is similar to that of endogenous deep integration except that instead of a single-step change in trading costs, and hence welfare, we postulate a continuous relationship between accumulated trade and well-being. Two forces are at work, each leading the optimum subsidy (CET) to fall through time. The optimum subsidy (CET) would fall even if the government were only concerned with maximizing current (instantaneous) welfare. But it would fall even faster if the government were concerned with maximizing the present value of (instantaneous) welfare.

In the case of current welfare maximization, starting from a steady state under free trade, home governments would subsidize partner imports according to equation 6 above. This would raise intrabloc imports and thereby the level of security capital. In the next period, some of this security capital would persist and so, given the diminishing marginal products of intrabloc imports on security and of security on welfare, the optimum subsidy would fall. In other words, as 
the level of security rises over time, some of the benefits of security are taken in the form of an increase in utility $V$ from a more efficient allocation of expenditure on consumption. This tendency to reduce the subsidy (or the CET) would continue until, in the new steady state, the new security capital generated each period just balances the depreciation of the old.

In the case of maximization of the present value of welfare, the dynamic effect reinforces the effect just discussed. In any period prior to attaining steady state, a subsidy on intrabloc imports not only increases current welfare via increased security but also increases future welfare by creating persistent security capital. Thus a rational government will subsidize imports more than is called for by current welfare-that is, it will have a subsidy (CET) exceeding that based on current considerations alone. This dynamic effect does not affect the steadystate level of the CET but does cause it to be approached more rapidly - the optimal dynamic CET would start higher and fall more rapidly than a CET based only on current welfare considerations.

Of course, new shocks could disturb these dynamic paths. For example, there may be times of crisis or reversal in which $S K$ suddenly falls. Then, the optimum CET would suddenly increase before starting to fall gradually again. If the crisis is temporary, with no impact on behavior, the CET eventually returns to its previous steady-state value. However, a deep crisis may affect security preferences or the $Z$-function in equation 1 as well as the security production function in equation 2 , with a permanent change in optimum external barriers.

\section{ENLARGEMENT AND DOMino EFFECTS}

Here we examine the impact of bloc enlargement on welfare and on the optimum CET. Assume that country 3 produces good $C$, exports it to countries 1, 2, and ROW, and imports goods $A, B$, and $R$.

\section{Symmetric Case}

First, assume that country 3 is symmetric with countries 1 and 2. Each country is assumed to enjoy the same degree of trust (or to suffer the same degree of mistrust) with respect to the other two.

Utility for the representative consumer in country $i$ is now

$$
\begin{aligned}
& U_{i}=V\left(A_{i}, B_{i}, C_{i}, R_{i}\right)+Z_{i}\left(S K_{i}\right) ; i=1,2,3 \\
& V_{i}, Z_{i}^{\prime}>0, V_{i j}, Z_{i}^{\prime \prime}<0, V_{i}(j=0)=\infty, V_{j} \equiv \partial V / \partial j ; \quad j=A_{i}, B_{i}, C_{i}, R_{i} .
\end{aligned}
$$

The level of security in the home country is positively related to imports from both partner countries, with $S K$ symmetric in both imports. That is,

$$
S K_{1}=S K\left(B_{1}, C_{1}\right) ; S K_{2}=S K\left(A_{2}, C_{2}\right) ; S K_{3}=S K\left(A_{3}, B_{3}\right) \text {. }
$$


Assume that the three countries impose optimum subsidies on trade with one another. Under symmetry, each country imposes the same subsidy rate $S$ as the other two and imposes the same subsidy on its imports from both partners. The same result is obtained with a common external tariff rate CET $=S /(1-S)$ and a tax rate $T=C E T$ on the consumption of the home good.

First, each member country's welfare rises when the RIA expands from two to three countries. In the two-country RIA case, the optimum subsidy is applied on the imports of one country only, while security benefits are obtained through imports from two countries. This case is equivalent to a constrained optimization in which one of the two subsidies is set (nonoptimally) equal to zero. This results in a level of welfare that is necessarily lower than under unconstrained optimization in the case of the three-country RIA, because in the latter case all externalities associated with the impact of imports on security are internalized. Consequently, starting from a two-member country RIA (say, countries 1 and 2), there is both a demand (by country 3 ) and a supply (by the RIA members) for enlargement. In this sense, there is a domino effect: if a two-country RIA does exist, the third country will join. However, if no two-country RIA exists, the three countries have an incentive to form a three-country RIA simultaneously. See Baldwin (1995) on domino effects.

We now turn to the impact of enlargement on the optimum CET. Define the optimum subsidy $S$ and optimum CET for a bloc with $k$ members by $S^{k}$ and $C E T^{k}$, respectively. What is the relationship between $S^{2}$ and $S^{3}$ (or $C E T^{2}$ and $\left.C E T^{3}\right)$ ? We show in appendix $C$ that $S^{k}$ need not increase with enlargement, although $S^{2}<S^{3}$ is likely to hold on average. This result generalizes to $S^{m-1}<S^{m}$ for a bloc expansion from $m-1$ to $m$ member countries in a world of $m$ symmetric countries $(m \geq 3)$, but not to $S^{k-1}<S^{k}$ for a bloc of size $k(k<m)$ in a world of $m$ symmetric countries. In other words, the result generalizes to any number of symmetric countries as long as the enlargement results in a bloc that includes all symmetric countries.

In a world of symmetric blocs with the optimum CET determined by market power, the CET increases with enlargement. In our model, the optimum CET need not increase with enlargement, although it is likely to do so on average.

\section{Asymmetric Case}

We now examine enlargement under asymmetry. Even though the main security concern in the 1950 s in Western Europe was with France and Germany, four countries (Belgium, Netherlands, Luxembourg, and Italy) joined France and Germany to form the European Economic Community. These four countries were smaller economically and weaker militarily. Similarly, Argentina and Brazil decided in the 1980s to integrate their economies, and Uruguay and Paraguay - two small neighbors-decided to join them and form Mercosur. And Chile and Bolivia recently signed free trade agreements with Mercosur. (On the impact on Chile of free trade agreements with Mercosur and NAFTA, see Harrison, Rutherford, and Tarr 1997 and Sapelli 1996.) 
Can our model predict anything about domino effects in such asymmetric situations? Imagine that countries 1 and 2 are symmetric and are large compared to country 3 (although they are still small economically compared to ROW). Assume that, given the small size of country 3, security in countries 1 and 2 depends on the level of trade between them and not on the level of trade with country 3 . Countries 1 and 2 have an incentive to form an RIA. The RIA reduces the level of security in country 3 because countries 1 and 2 export less to it. Thus country 3 has a stronger incentive to join in a three-country RIA than it did to join with either country 1 or 2 before they formed a two-country RIA. However, countries 1 and 2 have no incentive to allow country 3 to join the RIA; consequently country 3 may have to offer some compensation to countries 1 and 2 in order to be allowed to join. If the gains to country 3 from joining are larger than the losses (if any) to countries 1 and 2 (say, because they now trade more with country 3 and less among themselves), country 3 will compensate them and join the RIA. ${ }^{7}$ Whalley and Perroni (1994) note that compensation in the form of market access has become quite common recently, with large countries making significantly fewer market access concessions to smaller countries than vice versa.

\section{CONCLUSIONS}

This article has examined the logical implications of positive security externalities that may result from trade between suspicious neighbors. Adopting the common assumption that security with a neighbor increases as imports from that neighbor increase, and making no assumptions about the relative sizes of trade diversion and trade creation, we have shown that:

- The formation of a customs union, accompanied by appropriate domestic taxes, provides an optimum economic arrangement under symmetry and that the same holds for a free trade agreement under asymmetry.

- Deep integration (such as the EC-92) implies lower optimum external tariffs if it is exogenous, higher optimum external tariffs if it is endogenous and vanishes annually, and higher optimum external tariffs before deep integration but lower ones thereafter if deep integration is endogenous, takes place once and for all, and is permanent.

- If the level of security depends on past as well as current trade flows and is in steady state in the absence of trade barriers, then external tariffs result in an increase in security over time and the optimum external tariffs decline over time.

7. In some cases, the gains for country 3 may be very large. For instance, Paraguay suffered a devastating defeat in the 1860 s in its war (known in Spanish as "La Guerra de la Triple Alianza") with a coalition made up of Argentina, Brazil, and Uruguay. Most of its male population over 15 years of age perished in the conflict. Such a collective memory may provide a strong incentive to avoid potential conflicts in the future. 
- Enlargement of bloc size (in terms of the number of symmetric countries) implies higher welfare with an ambiguous impact on the optimum CET, although it is likely to be higher; and a form of domino effect exists.

Although externalities associated with security imply that RIAs may maximize welfare, our model suggests that the RIA is a transitory arrangement in the sense that optimum trade preferences are highest when the RIA is formed (when security is low) and decline over time. In other words, the RIA's optimal external trade policy becomes increasingly open over time.

\section{Two EXTENSIONS}

First, our model abstracts from defense expenditures as an alternative way to generate security. This was done for the sake of simplicity and to avoid gametheoretic issues at this stage. We recognize the importance of such issues, which are on our research agenda. In the case of defense expenditures, the cooperative solution is clearly optimal because the alternative may be a prisoner's dilemma situation with large defense expenditures, possibly without a higher level of security. In this case, the "peace dividend" following formation of an RIA may be substantial. (See Srinivasan 1994 for a discussion of these issues in the case of India and Pakistan.)

Second, our model assumes that imports from-rather than trade with-the partner country generates security benefits in the home country. Alternatively, one could assume that total trade (imports plus exports) with the partner generates security benefits. In that case, RIAs are likely to be superior to optimum intrabloc trade subsidies. There are both game-theoretic and practical reasons for this. First, each country will use a subsidy to maximize national welfare. However, individual decisions in the home country generate externalities not only for other individuals in the home country but also for individuals in the partner country because the home country's imports are the partner's exports and vice versa. Thus intrabloc trade subsidies that maximize national welfare generate a Nash equilibrium, with welfare and Nash subsidies lower than in a cooperative equilibrium that could be obtained by forming an RIA. Second, the Nash equilibrium implies subsidies on both imports and exports. Export subsidies are illegal for members of the General Agreement on Tariffs and Trade so that even the inferior Nash solution cannot be implemented. The superior cooperative solution implicit in the formation of an RIA (with appropriate domestic taxes) avoids this problem.

\section{APPENDiX A. ENDOGenous DeEP INTEGRATION}

Consider the case in which deep integration is related to current imports and has to be replenished every period. Assume that unit trading costs $C$ on imports from the partner are 


$$
C=C[S K(M)], \partial C / \partial M=(\partial C / \partial S K) S K^{\prime}<0
$$

where $M$ is the volume of imports from the partner (and $M=B_{1}=A_{2}$ under symmetry). There are two sources of positive externalities: a direct effect (equation 1) and an indirect effect deriving from lower unit costs on intrabloc trade. On the latter, the total trading cost, $T C$, on imports, $M$, from the partner and the marginal social cost of trading, $M S C$, are

$$
\begin{gathered}
T C=C[S K(M)] M \\
M S C=C(1+\varepsilon) \text { where } \varepsilon \equiv(\partial C / \partial M)(M / C)<0 .
\end{gathered}
$$

The representative consumer takes the private cost, $C$, of importing from the partner into account but not the (negative) effect on unit costs, $\varepsilon C$. This has to be added to the optimum subsidy, $S_{E}$, such that

$$
S_{E}=Z^{\prime}(\partial S K / \partial M) / \lambda-\varepsilon C>S
$$

(since $\varepsilon<0$ ) with $S$ defined in equation 5 . Equivalently, the optimum can be attained with a common external tariff, $C E T_{E}=S_{E} /\left(1-S_{E}\right)>C E T=\mathrm{S} /(1-S)$ and a tax on home consumption $T_{E}=C E T_{E}>T=C E T$.

\section{APPENDIX B. Dynamic AdJustments}

Assume that the level of $S K_{t}$ at time $t$ depends on the current flow of imports from the partner $(M)$ and on $S K_{t-1}$ at $t-1$, with a rate of depreciation of $S K$ equal to $\delta<1$. Expressing variables in continuous time, equation 2 becomes, under symmetry, the law of motion (equation B-1):

$$
\dot{S K}=F(M)-\delta S K ; \delta<1
$$

where $S K \equiv \partial S K$ / $\partial t$ is the time derivative of $S K, F(M)$ is the current gross addition to the stock of security capital (with $F^{\prime}>0$ ), and the subscript $t$ on $S K$ and $M$ has been deleted to simplify notation.

Start at steady state under free trade, with $S K=0$. With a subsidy on intrabloc imports, $S K$ accumulates, and its marginal utility $Z^{\prime}$ falls (equation 1 ). If governments are myopic and choose $S$ to maximize current welfare, $W=L U$, in each period, then from equation $5, S$ falls over time. However, optimizing governments also take into account the impact of current subsidies on the level of $S K$ and thus on future welfare.

Assume that the governments of countries 1 and 2 select an optimum time path for the subsidy $S$ on imports from the partner in order to maximize $\Phi$, the present value of $W=L U$. The Hamiltonian is

$$
H=\mathbb{W}(S K, S, t)+q \dot{S K}(S K, S, t)
$$


where $q$ is the marginal value of $S K, \partial \Phi_{\operatorname{MAX}} / \partial S K$, where $\Phi_{\operatorname{MAX}}$ is the maximum value of $\Phi$ obtained with the optimum path for $S$. The solution (from the maximum principle) is

$$
\begin{gathered}
\partial H / \partial q=\dot{S K}=F(M)-\delta S K \\
\partial H / \partial S=\partial W / \partial S+q(\partial \dot{S K} / \partial S)=0 \text { and } \\
\partial H / \partial S K=\partial W / \partial S K+q(\partial \dot{S} K / \partial S K)=-\dot{q} .
\end{gathered}
$$

From equation $\mathrm{B}-3, \partial \dot{S K} / \partial S=(\partial \dot{S K} / \partial M)(\partial M / \partial S)>0$. Thus, from equation B-4, $\partial W / \partial S<0$-that is, along the optimal path (which maximizes the present value of welfare), the subsidy exceeds the value necessary to maximize current welfare. If a government myopically maximizes current welfare without regard for future welfare, it chooses a subsidy level $S_{W}$ so that $\partial W / \partial S_{W}=0$. However, an increase in the subsidy also generates future welfare gains because it raises $M$ and thus raises $S K$. Thus the subsidy $S_{\Phi}$, which maximizes $\Phi$, is larger than the myopic $S_{W}$, which maximizes W. Consequently, $\partial W / \partial S<0$ at the optimum.

Assume that $S K$ is low (say, following a series of wars, such as in the 1950 s for France and Germany) so that $S K$ rises with imports $M$ between the two partners (equation B-3) and the value of $S K$ falls, $(\dot{q}<0)$. From equation B-4, a reduction in $q$ over time implies that $\partial W / \partial S$ falls over time in absolute value or becomes less negative because $\partial S K$ / $\partial S$ falls with $S K$ as well in absolute value. ${ }^{8}$ In other words, along its optimum path, $S_{\Phi}$ falls over time and approaches $S_{W}$. $S_{W}$ also falls as $S K$ rises because the marginal impact of $S K$ on $W$ falls with $S K$ $\left(Z^{*}<0\right)$. Equivalently, the optimum common external tariff (recall we are assuming symmetry) falls over time. The decline in the CET will stop once a steady state is attained, that is, once $S K=0$ (equation B-1).

\section{APPENDIX C. ENLARGEMENT}

We examine here the impact of enlargement on the optimum subsidy or CET. Equation 1 ' in section VI can be rewritten as

$$
U=V(A, B, C, R)+Z[S K(B, C)]
$$

where the subscript $i$ has been deleted for simplicity. Without loss of generality, we examine the issue from the viewpoint of country 1 . Define $S^{k}$ as the optimum subsidy in a bloc of $k$ countries $(k=2,3)$. From equation $\mathrm{C}-1$, we have

$$
\begin{aligned}
\mathrm{d} U / \mathrm{d} S & =[(\partial V / \partial A)(\mathrm{d} A / \mathrm{d} S)+(\partial V / \partial B)(\mathrm{d} B / \mathrm{d} S) \\
& +(\partial V / \partial C)(\mathrm{d} C / \mathrm{d} S)+(\partial V / \partial R)(\mathrm{d} R / \mathrm{d} S)] \\
& +Z^{\prime}[(\partial S K / \partial B)(\mathrm{d} B / \mathrm{d} S)+(\partial S K / \partial C)(\mathrm{d} C / \mathrm{d} S)] .
\end{aligned}
$$

8. $\partial \dot{S K} / \partial S=(\partial \dot{S K} / \partial S K)(\partial S K / \partial M)(\partial M / \partial S)=-\delta(\partial S K / \partial M)(\partial M / \partial S)$. The depreciation rate $\delta$ is constant, $\partial M / \partial S$ is independent of $S K$ since $U$ is additive, and $\partial S K / \partial M=S K^{\prime}$ falls with $M$, so that $\partial S K / \partial S$ falls with $S K$ in absolute value. 
Because income is measured at world prices, $Y_{1}=A=a L_{1}$ does not change with the subsidy, and because all world prices are unity, balanced trade implies that $\mathrm{d} A+\mathrm{d} B+\mathrm{d} C+\mathrm{d} R=0$. Assume that we start with $S=S^{3}$ and apply it to imports of both $B$ and $C$. Because $S^{3}$ is an optimum, $\mathrm{d} U / \mathrm{d} S=0$. Given symmetry, $B=C>A=R, \partial V / \partial A=\partial V / \partial R>\partial V / \partial B=\partial V / \partial C, \mathrm{~d} B / \mathrm{d} S=\mathrm{d} C / \mathrm{d} S=$ $-\mathrm{d} A / \mathrm{d} S=-\mathrm{d} R / \mathrm{d} S>0$, and $\partial S K / \partial B=\partial S K / \partial C$. Substituting these in equation $\mathrm{C}-2$, we have

$$
\mathrm{d} U / \mathrm{d} S=2(\mathrm{~d} B / \mathrm{d} S)\left[(\partial V / \partial B-\partial V / \partial A)+Z^{\prime}(\partial S K / \partial B)\right]=0 .
$$

Alternatively, assume that $S=S^{3}$ applies only to imports of $B$ and that the subsidy on imports of $C$ is set equal to zero. Such a configuration of subsidies is not an optimum, so $\mathrm{d} U / \mathrm{d} S \neq 0$. In this case, $A=C=R<B, \mathrm{~d} A / \mathrm{d} S=\mathrm{d} C / \mathrm{d} S=$ $\mathrm{d} R / \mathrm{d} S<0, \mathrm{~d} B / \mathrm{d} S=-\mathrm{d} A / \mathrm{d} S-\mathrm{d} C / \mathrm{d} S-\mathrm{d} R / \mathrm{d} S=-3(\mathrm{~d} A / \mathrm{d} S)$, and $\partial V / \partial A=$ $\partial V / \partial C=\partial V / \partial R$. Substituting in equation $\mathrm{C}-2$, we have

$$
\begin{aligned}
\mathrm{d} U / \mathrm{d} S & =(\mathrm{d} B / \mathrm{d} S)\left[(\partial V / \partial B-\partial V / \partial A)+Z^{\prime}(\partial S K / \partial B)\right] \\
& -\left(Z^{\prime} / 3\right)(\partial S K / \partial C) .
\end{aligned}
$$

The objective is to evaluate $d U / d S$ in equation C-4. If the sign were negative (positive), then $S$ would have to be reduced (increased) to reach the optimum subsidy, $S^{2}$, in the two-country RIA case, that is, $S^{2}<S^{3}\left(S^{2}>S^{3}\right)$.

Note the similarities between equations $C-3$ and $C-4$. The term $\Gamma(A, B, C, R)$ $\equiv\left[(\partial V / \partial B-\partial V / \partial A)+Z^{\prime}(\partial S K / \partial B)\right]=0$ in equation C-3. If both equations were evaluated at the same values for $A, B, C$, and $R$, then $\mathrm{d} U / \mathrm{d} S$ in equation C-4 would be $\mathrm{d} U / \mathrm{d} S=\Gamma(A, B, C, R)-\left(Z^{\prime} / 3\right)(\partial S K / \partial C)=-\left(Z^{\prime} / 3\right)(\partial S K / \partial C)<0$, and thus $S^{2}<S^{3}$. However, equations $C-3$ and $C-4$ are not evaluated at the same values for $A, B, C$, and $R$, so $\Gamma(A, B, C, R)$ is not necessarily equal to zero in equation $\mathrm{C}-4$.

We now show that the value of $\Gamma(A, B, C, R) \equiv(\partial V / \partial B-\partial V / \partial A)+Z^{\prime}(\partial S K /$ $\partial B)$ can be either positive or negative when evaluated at the quantities prevailing in equation C-4. The difference between equations C-3 and C-4 is that the subsidy at the rate $S^{3}$ in equation $C-3$ is set equal to zero on good $C$ in equation C-4. Thus, $B$ and $A$ are both larger in equation C-4, $\partial V / \partial B$ and $\partial V / \partial A$ are both smaller, and the impact on $(\partial V / \partial B-\partial V / \partial A)$ is ambiguous. The impact on $Z^{\prime}(\partial S K / \partial B)$ is ambiguous as well. At the larger value of $B$ in equation $C-4$, $\partial S K / \partial B$ is likely to be smaller, but because $S K$ is also likely to be smaller, $Z^{\prime}$ is larger, and the impact on $Z^{\prime}(\partial S K / \partial B)$ is ambiguous. ${ }^{9}$ In other words, the sign

9. Comparing equilibria in equations $C-3$ and $C-4$, a second-degree Taylor expansion of the difference in $S K$ is $\Delta S K=[\Delta B(\partial S K / \partial B)+\Delta C(\partial S K / \partial C)]+\left[\Delta B^{2}\left(\partial^{2} S K / \partial B^{2}\right)+\Delta C^{2}\left(\partial^{2} S K / \partial C^{2}\right)\right] / 2+\left[\Delta B \Delta C\left(\partial^{2} S K /\right.\right.$ $\partial B \partial C)]$. What is the sign of $\triangle S K$ ? The first term in square brackets is negative. To show this, note that $B=C$ in equation $C-3$ so that $\partial S K / \partial B=\partial S K / \partial C$, but $\Delta B<-\Delta C$. (The increase in $B$ is smaller than the decline in $C$ because removing the subsidy on $C$ also leads to a rise in consumption of $A$ and $R$, and from the budget constraint, $-\Delta C=\Delta A+\Delta B+\Delta R>\Delta B$.) The second term in square brackets is negative 
of $\Gamma(A, B, C, R)$ in equation $C-4$ is ambiguous: For some functional forms of $V$, $Z$, and $S K, \Gamma(A, B, C, R)$ will be negative, while for others, it will be positive or zero.

One would need to know the exact functional forms of $V, Z$, and $S K$ in order to determine the sign of $\Gamma(A, B, C, R)$ in equation $C-4$. However, under symmetry of the positive and negative values for $\Gamma(A, B, C, R)$ across all functional forms for $V, Z$, and $S K$, one may expect its average value to be zero. (Strictly speaking, whether the average value of $\Gamma(A, B, C, D)$ in equation $C$-4 is zero or not depends on the definition of the domain of the functions $V, Z$, and $S K$.) And because $-\left(Z^{\prime} / 3\right)(\partial S K / \partial C)<0$, one may expect the average value of $\mathrm{d} U / \mathrm{d} S$ to be negative. This implies that, on average, $S^{2}<S^{3}$.

It is easy to show that the result generalizes to $S^{m-1}<S^{m}$ for a bloc expansion from $m-1$ to $m$ member countries in a world of $m$ symmetric countries $(m \geq 3)$, but not, unfortunately, that it generalizes to $S^{k-1}<S^{k}$ for a customs union of size $k(k<m)$ in a world of $m$ symmetric countries.

\section{REFERENCES}

The word "processed" describes informally reproduced works that may not be commonly available through library systems.

Arad, Ruth, and Arye L. Hillman. 1979. "Embargo Threat, Learning, and Departure from Comparative Advantage." Journal of International Economics 9(May):26575.

Baldwin, Richard E. 1995. “A Domino Theory of Regionalism.” In R. E. Baldwin, Pertti Haaparanta, and Jaakko Kiander, eds., Expanding Membership in the European Union. Cambridge, U.K.: Cambridge University Press.

Bastian, Jens. 1996. "Trade Diplomacy and Regional Integration." Report on a World Bank workshop, July, London School of Economics. Processed.

Becker, Gary S. 1996. The Making of Preferences and Values. Cambridge, Mass.: Harvard University Press.

Bhagwati, Jagdish. 1987. "The Generalized Theory of Distortions and Welfare." In Jagdish N. Bhagwati, ed., International Trade: Selected Readings, $2 \mathrm{~d}$ ed. Cambridge, Mass.: MIT Press.

Bhagwati, Jagdish, and Arvind Panagariya. 1996. "Preferential Trading Areas and Multilateralism: Strangers, Friends, or Foes." In Jagdish Bhagwati and Arvind Panagariya, eds., The Economics of Preferential Trade Agreements. Washington, D.C.: American Enterprise Institute Press.

because the second derivatives are negative. (Intuitively, as $C$ falls, $\partial S K / \partial C$ rises so that the loss in $S K$ from additional reductions in $C$ increases; similarly, the gains in $S K$ from increases in $B$ decline with $B$.) However, $\partial^{2} S K / \partial B \partial C$ may be negative-if country 1 is less concerned about security with respect to country 2 (equation 3 ), if security with respect to country 3 (equation 2 ) is higher-and the third term in square brackets is then positive. Thus, although it may seem likely that removing the subsidy on imports of good $C$ results in $\Delta S K<0$, this need not be the case. However, no matter what the sign of $\Delta S K$, the fact remains that the difference in $Z^{\prime}(\partial S K / \partial B)$ is ambiguous. The reason is that with an ambiguous change in $S K$, the changes in both $Z^{\prime}$ and in $\partial S K / \partial B$ are ambiguous. 
Bliss, Christopher. 1994. "Trade Blocks and Migration." Economic Theory and Policy for Trading Blocks. Manchester, U.K.: Manchester University Press.

Chan, Steve. 1984. "Mirror, Mirror on the Wall . . . Are the Freer Countries More Pacific?" Journal of Conflict Resolution 28:617-48.

Ethier, Wilfred. 1996. “Multilateral Roads to Regionalism.” Department of Economics, University of Pennsylvania, Philadelphia. Processed.

Gasiorek, Michael, Alasdair Smith, and Anthony J. Venables. 1992. “1992: Trade and Welfare: A General Equilibrium Model." In L. Alan Winters, ed., Trade Flows and Trade Policy after 1992. London: Cambridge University Press.

Gasiorowski, Mark, and Solomon Polachek: 1982. "Conflict and Interdependence: EastWest Trade Linkages in the Era of Détente." Journal of Conflict Resolution 26:709-29.

Haas, Ernst. 1958. The Uniting of Europe. London: Stevens and Sons.

Harrison, Glenn W., Thomas F. Rutherford, and David Tarr. 1996. "Increased Competition and Completion of the Market in the European Union: Static and Steady-State Effects." Joumal of Economic Integration 11(3):332-65.

- 1997. "Trade Policy Options for Chile: A Quantitative Evaluation." Policy Research Working Paper 1783. Policy Research Department, World Bank, Washington, D.C. Processed.

Hillman, Arye L., and Ngo van Long. 1983. "Pricing and Depletion of an Exhaustible Resource When There Is Anticipation of Trade Disruption.” Quarterly Journal of Economics 98(May):215-33.

Hirschman, Albert O. 1981. Essays in Trespassing: Economics to Politics and Beyond. Cambridge, U.K.: Cambridge University Press.

- 1982. "Rival Interpretations of Market Society: Civilizing, Destructive, or Feeble?" Journal of Economic Literature 20:1463-84.

Hull, Cordell. 1948. The Memoirs of Cordell Hull. New York: Macmillan.

Jones, Ronald. 1993. "Discussion." In Jaime de Melo and Arvind Panagariya, eds., New Dimensions in Regional Integration. Cambridge, U.K.: Cambridge University Press.

Kant, Immanuel. 1992. Perpetual Peace: A Philosophical Essay. Bristol: Thoemmes Press.

Keynes, John Maynard. 1919. The Economic Consequences of the Peace. London: Macmillan.

Krugman, Paul R. 1991. "Is Bilateralism Bad?" In Elhanan Helpman and Assaf Razin, eds., International Trade and Trade Policy. Cambridge, Mass.: MIT Press.

Machlup, Fritz. 1977. A History of Thought on Economic Integration. London: Macmillan.

Mansfield, Edward D. 1993. "Effects of International Politics on Regionalism in International Trade." In Kym Anderson and Richard Blackhurst, eds., Regional Integration and the Global Trading System. New York: St. Martin's Press.

Mansfield, Edward D., and Rachel Bronson. 1997. “Alliances, Preferential Trading Arrangements, and International Trade." American Political Science Review 91(1, March): 94-107.

Page, Sheila. 1996. “Intensity Measures for Regional Groups.” Paper prepared for EADI ninth general conference, September, Vienna. Processed.

Polachek, Solomon W. 1992. "Conflict and Trade: An Economics Approach to Political - Interactions." In Walter Isard and Charles H. Anderton, eds., Economics of Arms Reduction and the Peace Process. Amsterdam: North-Holland. 
1996. "Why Democracies Cooperate More and Fight Less: The Relationship between International Trade and Cooperation." Review of International Economics.

Puga, Diego, and Anthony J. Venables. 1997. "Preferential Trading Arrangements and Industrial Location." Journal of International Economics 43:347-68.

Rieben, Henri, Jean Monnet, and G. A. Chevallaz. 1971. Jean Monnet. Lausanne: Centre de Recherches Européennes.

Sapelli, Claudio, ed., 1996. Chile en el NAFTA: Acuerdos de libre comercio versus liberalisación unilateral. Santiago: International Center for Economic Growth.

Schiff, Maurice. 1992. "Social Capital, Labor Mobility, and Welfare: The Impact of Uniting States." Rationality and Society 4(2, April):157-75.

- 1995. "Capital socio-culturel, diversité ethnique et réforme en Afrique." Revue d'Economie du Développement 3:41-53.

- 1996. "Social Capital, Trade, and Optimal Migration Policy." International Economics Department, World Bank, Washington, D.C. Processed.

- 1997. "Small Is Beautiful: Preferential Trade Agreements and the Impact of Country Size, Market Share, and Smuggling." Journal of Economic Integration 12(3):359-87.

. 1998. "Ethnic Diversity and Economic Reform in Sub-Saharan Africa." Journal of African Economics 17(3, May). Forthcoming.

Skidelsky, Robert. 1992. Jobn Maynard Keynes: The Economist as Saviour 1920-1937. London: Macmillan.

Smith, Alasdair, and Anthony Venables. 1988. "Completing the Internal Market in the European Community: Some Industry Simulations." Discussion Paper Series 233. Centre for Economic Policy Research, London. Processed.

Srinivasan, T. N. 1994. "Regional Trading Arrangements and Beyond. Exploring Some Options for South Asia: Theory, Empirics, and Policy." Report IDP-142. South Asia Office of the Chief Economist, World Bank, Washington, D.C. Processed.

Swann, Dennis. 1992. The Economics of the Common Market, 7th ed. Harmondsworth: Penguin.

Whalley, John, and Carlo Perroni. 1994. “The New Regionalism: Trade Liberalization or Insurance?” NBER Working Paper 4626. National Bureau of Economic Research, Harvard University, Cambridge, Mass. Processed.

Winters, L. Alan. 1989. "The 'So-Called Non-Economic Objectives' of Agricultural Policy.” OECD Economic Studies 13:237-66.

- 1991. "Digging for Victory: Agricultural Policy and National Security." The World Economy 13:170-90.

- 1997. "What Can European Experience Teach Developing Countries about Integration?" The World Economy 20:889-912. 